\title{
The effect of a period of aquatic therapy exercise on the quality of life and depression in aged males suffering from chronic physical pains
}

\author{
Y. Khanjari (M. A), R. Garooei (M. A) \\ University of Tehran, University of Kharazmi \\ E-mail address: ykhanjari@gmail.com
}

Keywords: Aging, Chronic physical pain, Hydrotherapy, Quality of life, Depression

\begin{abstract}
Aging is a stage of life that increases the risk of physical diseases, some of which are chronic and can affect different dimensions of life's quality and the status of psychological factors in these patients. In addition to medical supports, it is essential to provide sport complexes in accordance with the physical and mental condition of these patients. The aim of this study was to evaluate the effect of a period of aquatic therapy exercise on the quality of life and depression in aged males suffering from chronic physical pains.

In a semi-experimental study, 30 aged males who voluntarily referred to Niyayesh health center of Shiraz were selected. They were randomly divided in to two groups; experimental $(n=15)$ and control $(n=15)$. Subjects of aquatic therapy exercise were involved in an 8-week-activity in water; 3 sessions per week each lasting approximately 50 to 70 minutes. At the same time, the control group was only followed-up and was not engaged in any exercise during this period. The variables of the quality of life and depression among the patients were measured by standard questionnaires in the beginning and end of the eight-week-aquatic therapy exercise.

Results of this study showed that aquatic therapy exercise can be used as an effective and helpful method to promote public health in aged males suffering from chronic physical pains because it leads to the improvement of multi-dimensional variables of quality of life and depression in the patients.
\end{abstract}

\section{INTRODUCTION}

The population in Iran is ageing as the current statistics show that the population of those over 60 is about to become level to the population of children under 5, and it is estimated that in the year 2050 the population of the seniors will be several times that of the children under 5 , with the population of seniors reaching two billions 50 years from now. ${ }^{1}$ According to the current statistics, Iran's population will tend towards ageing in the years to come ${ }^{2}$. Therefore, the period of aging itself needs to be investigated as a stage in one's life. The process of ageing is the gradual decrease in the function of the bodily systems including cardiovascular, respiratory, urogenital, endocrine, and immunity system. An adult would turn into a weak person with a decrease in various physiological capabilities and an increase in susceptibility to a host of diseases and death through the process of ageing ${ }^{3}$.This phenomenon does not characterize a certain group; all individuals will gradually experience it $^{4}$. What matters is that senility will cause a decrease in mobility, little income, insufficient care, and increase in outbreak of chronic physical and mental diseases ${ }^{5}$. As a result, the researchers ${ }^{6}$ have increasingly come to the belief that health-improving behaviors in this phase gain higher momentum with regard to the maintenance of individual function and independence along with an increase in the quality of their lives.

A manifold of problems and difficulties cause a decrease in the quality of life for the elderly ${ }^{7}$. Chronic diseases and failures are among these prevalent problems. In this regard, a study by Barry (2000) showed that around $8 \%$ of the elderly people are suffering from at least one chronic disease like arthritis, blood pressure, cardiac diseases, or sensory disorder ${ }^{8}$. Another study by Conger and Moore (2002), too, showed that elderly people suffer from various sensory disorders such as visual, auditory, and the like resulting in limitation of social engagement coupled with gradual increase in dependence to others, and decrease in the quality of life ${ }^{9}$. Matteson \& 
McConnell (1988) are of the opinion that these problems end in diminishing tolerance of unwanted stimuli, poor performance in unsuitable environmental conditions, depression, increased level of stress, incompatible adaptive reactions, loss of self-esteem, and even the death among the elderly ${ }^{10}$. These problems cause this group to be the major candidate for nursing and medical care. Pain is the common complaint in senility medicine. The statistics indicate, for instance, that pain in the area of back renders 7 million people in the US incapable, annually. They also indicate more than 8 million visits to the doctors are due to pain-induced problems ${ }^{11}$. The most common age for being stricken by pain is the senility period, probably because with age, tolerance of pain reduces. Similarly, Mirzamani, Hellisaaz, Sadidi, \& Safari (2008) found that compared to the young people, the elderly experience a significantly higher pain which results in a greater interference of pain in their daily life and subsequent dependence to the spouse or someone closely related in their lives ${ }^{12}$. The elderly experience such chronic pains as depression, disordered interpersonal (particularly family) relations, sleep disorder, fatigue, and decrease in physical and psychological functions. A significant portion of the population with chronic pain suffers from depression, maladjustment, and stress in social and family environment ${ }^{13}$.

Quality life constitutes one of the variants related to the elderly life. Investigating its interactive impact on other psychological constituents like depression has been highly regarded by the researchers and authorities. Newman, Struck, Wright, \& Rice (1984) state that the quality of life and social support have a direct effect on physical complaints of the individuals so that those with a high quality of life are far less susceptible to disease in case of an unpleasant experience ${ }^{14}$.

Nowadays, with an increase in life expectancy index, another issue of importance has been raised under the title of the way of living, namely, the quality of life and its central component, the mental health. Since the quality of life possesses several aspects such as physiological aspects, function, and existence of the individual ${ }^{9}$, Andrew ${ }^{15}$ is of the opinion that in the course of treatment and care for the elderly, one needs to consider the factors effective in the quality of their lives, and the care solutions would prove effective only when they improve the quality of the elderly life. Thus, the quality of life is a vast concept involving all aspects of life which include but are not restricted to health ${ }^{16}$. The investigations demonstrate that conducting research on the quality of life along with its numerous aspects is a matter of interest to the researchers, so that the existing articles under the title of "the quality of life" which relate to health have seen an increase from $21 \%$ to $67 \%$ within the period 1985-1995 ${ }^{17}$.

According to the statistics mentioned in the reference books, depression serves as one of the commonest psychiatric disorders among the elderly. Outbreak of the marked clinical symptoms of depression among the elderly residing in the community is at 8 to $15 \%$, and among those institutionalized in the nursing homes is around $30 \%{ }^{18}$. Depression in the final stage of life is not a natural part of the aging, and in fact, it is more than a transient mood ${ }^{19}$. A study by Manzoori ${ }^{20}$ titled $^{2}$ "Depression and the Related Factors among the Elderly in Isfahan in 2007" demonstrated that $63.7 \%$ of the elderly living in the community developed depression. Factors such as depression, dementia, and stress affect decision-making on the possibility of domestic management of physical illnesses and doing the daily works which might result in trusting the elderly to the nursing houses and heavy costs of care in such services due to high physical and mental pressures on the family members. Therefore, dealing with the mental problems of the elderly such as depression appears to be one of the future necessities of the health systems. Preserving the physical performance for the daily activities in the elderly people with chronic diseases is necessary as regular exercise to maximize the physical strength could affect the decrease in morning pain, fatigue, and stiffness ${ }^{21}$. Physical therapy through strengthening the muscles around the joints and lifting off the pressure on them is effective in reducing the pain and increasing the range of movement in these patients. Now, if these exercises are done in the water, with respect to the qualities of water in inducing resistance, alleviating and reducing the pressure on the joints as well as its refreshing quality, the exercise would be carried out easier and with less damage with better result in improving the physical strength, respiratory condition, reduced stress and depression, and upgrading the physical activity of the patients compared to when these exercises are done on the land ${ }^{22}$. 
Hydrotherapy is a suitable non-pharmaceutical treatment that can cause a pain reduction, an increase in the flexibility of the muscles, joints, movement of the bones, reduction of muscular spasms, and increase in individual's overall strength ${ }^{23}$. In their study, Abbasi et. al. (2012) analyzed the effect of physical therapy in water on the stability of the elderly men. The result of their study indicated that hydrotherapy has a positive effect on walking, reduction in falling down, and consequently, the quality of their lives ${ }^{40}$.Geytenbeek (2002) has stated in another study that hydrotherapy can have positive effects on self-confidence and depression, and a decrease in relapse of chronic illnesses like rheumatism, arthritis, and backache as well as on the diseases of nervous system such as MS and strokes ${ }^{24}$. Moreover, Mcllveen and Robertson (1998) showed in their study that hydrotherapy is a useful and economic method in regulating the symptoms such as pain, muscular spasm, dysfunction, and imballance ${ }^{23}$. The National Foundation for Arthritis in United States suggested a water exercise program in 1997 to improve the quality of life in the community of the elderly patients with arthritis ${ }^{43}$. Heywood and Hinman (2007) also demonstrated that water exercise programs has proved effective in relieving the pain and improving the quality of life for the elderly with chronic illnesses by strengthening the muscles around the joints and lifting the pressure off them ${ }^{44}$. In South Korea, a study conducted byKang (2008) indicated that water exercise programs have been extensively administered in recent years for treating the chronic elderly illnesses like discopathy, and osteoarthritis ${ }^{45}$.Wang et.al. (2011) exhibited in their study that water exercise has little to medium effects on the elderly performance and the quality of life and also a partial effect on the pain intensity among the elderly patients with chronic pains. However, the studies conducted so far in that case are too little for definitive conclusions ${ }^{46}$. Another study titled "Hydrotherapy versus Conventional Land-Based Exercise for the Management of Patients with Osteoarthritis of the Knee: a Randomized Clinical Trial" by Silva et.al. (2008) maintained that water exercise brings about a significant progress in alleviating the intensity of pain, disease symptoms, improving the motor performance and the quality of life for those suffering from knee osteoarthritis ${ }^{47}$. Yet, it was shown by Lund et.al. (2008) in analyzing the effect of aquatic and landbased exercises that water exercise does not induce a significant improvement in the pain intensity, symptoms of illness, motor performance, and quality of life for those of the elderly with knee osteoarthritis $^{48}$.

Although doing classic land-based exercises is beneficial for many old people, specific medical conditions such as osteoporosis, arthritis, stroke, and fatness are present among them which dwindle their ability to participate in these exercise programs or hinder their performance in these exercises. Given its unique properties like buoyancy, viscosity, and hydrostatic pressure, the water is a perfect environment to increase self-confidence and reduce the effect of weight tolerance due to gravity allowing the elderly to do physical exercise in a pain-free environment ${ }^{25}$.

In spite of the benefits mentioned and the patients' tendency to do water-based instead of land-based exercise, and also prescriptions by sports scientists and medical doctors regarding the importance of water exercise in preventing and curing numerous elderly illnesses, unfortunately, few studies have been conducted in this regard ${ }^{24}$. Generally speaking, fewer studies investigating the effect of hydrotherapy on the elderly have been conducted in Iran, being mainly related to the physical factors. Thus, in the present study, the researcher is determined to analyze the psychological factors among the elderly which to some extent might account for its distinction from other previous research (see 12, 23, 24, 40, 41).So, due to the fact that numerous annoying symptoms of chronic physical illnesses among the elderly are capable of dropping the quality of their lives and depression, the researchers aims at investigating the effect of an eight-week course of water-based physical therapy on the level of depression and the quality of life among the old people with chronic physical pain.

\section{METHODS AND MATERIALS}

The data population of the study consisted of all elderly males with chronic physical pain who referred to Niyayesh Health Center. These elderly people were chosen from among those who developed chronic physical pains such as chronic backaches (e.g. lumbar disc, spinal stenosis, and 
protracted spasms), chronic knee pains (e.g. joint wear, osteoarthritis), rheumatoid arthritis, and cardiovascular problems. It is worth mentioning that the majority of the subjects in this study suffered from backache and chronic knee pain, all being admitted with their medical certificates. The health center in question has been built with a suitable environment specified for hydrotherapy for the patients, particularly the elderly people. The subjects included 30 elderly males with moderate or severe pain being selected as statistical samples in an available and targeted fashion, and then 15 individuals were randomly classified into the experimental group and the other 15 into control group. Subsequent to filling out the consent form, the subjects participated in the research quite voluntarily. After selecting the patients, the relevant questionnaires were handed to them in order to collect demographic as well as other data required for the research. Then, the subjects in the experimental group underwent physical therapy under the supervision of a trainer for 8 weeks. The questionnaires included a researcher-made questionnaire with 36 questions about the quality of life and the depression. The 36-question short form questionnaire (SF-36) is a means of general measurement of health able to measure the quality of life efficiently. It is a highly applied means of general evaluation of health worldwide, and this is due to its comprehensiveness and brevity. It contains 36 questions on 8 dimensions including physical performance, limitations in performance due to physical problems, physical pain, general health, feeling of exhilaration, mental health, limitations in performance with regard to the emotional issues and social performance. Grades 0 to 100 were designated to the sum total of the eight dimensions of health, with the higher grades signaling a better health condition ${ }^{26}$. The validity and reliability of the questionnaire have been established in numerous studies, and even its Farsi version is available and of acceptable validity and reliability ${ }^{27}$.

The depression questionnaire no.1 that contains 21 questions has been made with the intention of evaluating the feedbacks and symptoms of the depressed patients, and its material has been provided based on observation and summarization of common attitudes and signals among the depressed psychiatric patients ${ }^{28,29}$. Various studies have also been conducted in Iran measuring the psychometric qualities of this instrument. Among them the study by Tashakkori and Mehriar (1986) could be mentioned with a reliability coefficient of 0.078 in Iran together with the studies by Vahabzadeh (1973) and Chegini (2002) that have reported a high validity (0.70 - 0.90)for questionnaire no. $1^{32}$. The minimum grade in this test is zero and the maximum is 63 . By adding up the grades of every individual in each case the individual's grade would be obtained directly. The following grades could be used to show the general level of depression: 0 to 13 is for no or the least depression, $14-19$ for slight depression, $20-28$ for medium depression, and $29-63$ for severe depression $^{30}$.

The course of hydrotherapy in the pool consisted of 24 sessions that were held in three sessions of 50 to 70 minutes a week where 40 to 60 percent of the maximum storage heart beat was performed progressively. The exercise session in water involved three sections, namely, warm-up, main section, and cool-down. The warm-up section consisted of 15 minutes of walking in the water and some stretching. The main section of the program involved performing 8 simple exercises in upper and lower organs for 15 minutes and using hydrotherapy machines in water including stationary bike, paddle, step, and light foam weights for reinforcing the subjects' muscles. It is noteworthy that all the machines were installed in the water, and the subjects worked with each machine for 2 to 3 minutes keeping a one minute interval between each exercise. The subjects were asked to perform the exercises up to the pain threshold. Finally, to restore the subjects to the initial condition at the end of each session, some stretching and flexibility moves were performed for 5 minutes. Subjects in the control group did not go through any regular exercise in this period. After the end of 8 weeks of physical exercise in water, the subjects were once again provided with the related questionnaires. In the end the collected data were refined using descriptive statistics. Data distribution naturalness test was conducted by means of Kolmogorof-Smirnov test, and the mean and standard deviation of the data were calculated using descriptive statistics methods, and the groups were compared through inferential statistics using dependent t-test and covariance analysis, with the level of significance determined at $(\mathrm{P}<0.05)$. 


\section{RESULTS}

The mean and standard deviation of physical qualities of the subjects have been given in table 1. In tables 2 and 3 the findings on different areas of depression and the quality of life in the phases before and after the water-based course of physical therapy have been provided for the experimental and the control group, respectively. The findings in the tables 2 and 3 indicate a significant improvement in the experimental group $(\mathrm{P}<0.05)$ in terms of depression and the quality of life while no significant change has been resulted for the control group $(\mathrm{P}>0.05)$.

The covariance analysis of different areas of depression and the quality of life in the groups under investigation after 8 weeks of water-based physical therapy have been provided in table 4 that suggest a significant in the post-test between both groups.

Table 1. Mean and standard deviation of the physical qualities of the subjects

\begin{tabular}{|c|c|c|}
\hline \multirow{2}{*}{ Physical Qualities } & \multicolumn{2}{|c|}{ Standard Deviation \pm Mean } \\
\cline { 2 - 3 } & Experimental Group & Control Group \\
\hline Age(year) & $70 \pm 8 / 6$ & $66 / 7 \pm 7 / 3$ \\
\hline Length(centimeter) & $167 \pm 6 / 4$ & $169 \pm 5 / 8$ \\
\hline Weight(km) & $71 \pm 10 / 5$ & $69 / 55 \pm 9 / 7$ \\
\hline BMI(body mass index) & $30 \pm 3 / 2$ & $31 / 20 \pm 1 / 95$ \\
\hline
\end{tabular}

As for the findings in table 2, there is a significant difference between the mean of different areas of depression and the quality of life in the experimental group before and after a course of water-based physical therapy. In other words, a significant improvement is observed in all the variables under scrutiny following 8 weeks of water-based physical therapy $(\mathrm{P}<0.05)$.

Table 2. Comparison of areas of depression and the quality of life in the experimental group before and after a course of water-based physical therapy

\begin{tabular}{|l|c|c|c|c|c|}
\hline \multirow{2}{*}{\multicolumn{1}{|c|}{ variables }} & \multicolumn{2}{c|}{ Standard Deviation \pm Mean } & \multicolumn{3}{c|}{ Correlated t-test } \\
\cline { 2 - 5 } & Before & After & significance & t-value & df \\
\hline Physical performance & $45 \pm 25 / 48$ & $61 / 45 \pm 21$ & $0 / 038$ & $2 / 28$ & 14 \\
\hline Physical Health Limitation & $/ 30 \pm 18 / 85$ & $49 \pm 20 / 45$ & $0 / 009$ & $3 / 56$ & 14 \\
& 32 & & & & \\
\hline $\begin{array}{l}\text { Emotional Problems } \\
\text { Limitation }\end{array}$ & $\begin{array}{c}136 \pm 19 / 65 \\
37\end{array}$ & $58 / 10 \pm 17 / 32$ & $0 / 025$ & $4 / 30$ & 14 \\
\hline Strength/Fatigue & $30 \pm 30 / 75$ & $55 / 20 \pm 29 / 55$ & $0 / 007$ & $4 / 15$ & 14 \\
\hline Mental Health & $/ 38 \pm 24 / 65$ & $58 / 58 \pm 26 / 64$ & $0 / 031$ & $2 / 45$ & 14 \\
\hline Social Performance & 36 & & & & \\
\hline Pain & $/ 28 \pm 27 / 89$ & $49 \pm 19 / 14$ & $0 / 015$ & $3 / 39$ & 14 \\
\hline General Health & 29 & & & & \\
& $/ 59 \pm 26 / 15$ & $54 / 56 \pm 25 / 54$ & $0 / 030$ & $5 / 25$ & 14 \\
\hline Quality of Life in General & 33 & & & & 14 \\
\hline Depression & $36 / 15 \pm 18$ & $57 / 25 \pm 12 / 09$ & $0 / 001$ & $5 / 80$ & 14 \\
\hline
\end{tabular}

The findings in table 3 indicate that no significant difference exists between different areas of depression and the quality of life in the control group $(\mathrm{P}>0.05)$. 
Table 3. Comparison of different areas of depression and the quality of life in the control group

\begin{tabular}{|l|c|c|l|l|l|}
\hline \multirow{2}{*}{\multicolumn{1}{c|}{ variables }} & \multicolumn{2}{c|}{ Standard Deviation \pm Mean } & \multicolumn{2}{c|}{ Correlated t-test } \\
\cline { 2 - 6 } & Before & After & significance & t-value & \multicolumn{1}{c|}{ df } \\
\hline Physical performance & $48 / 47 \pm 18 / 15$ & $49 / 21 \pm 16 / 25$ & $0 / 67$ & $0 / 57$ & 14 \\
\hline Physical Health Limitation & $41 / 25 \pm 28 / 56$ & $39 / 25 \pm 14 / 26$ & $0 / 82$ & $0 / 39$ & 14 \\
\hline $\begin{array}{l}\text { Emotional Problems } \\
\text { Limitation }\end{array}$ & $37 / 38 \pm 21 / 36$ & $34 / 25 \pm 18 / 18$ & $0 / 367$ & $0 / 75$ & 14 \\
\hline Strength/Fatigue & $37 \pm 15 / 14$ & $40 / 51 \pm 28 / 24$ & $0 / 397$ & $1 / 21$ & 14 \\
\hline Mental Health & $45 / 57 \pm 25 / 14$ & $43 / 84 \pm 14 / 21$ & $0 / 095$ & $1 / 01$ & 14 \\
\hline Social Performance & $30 / 12 \pm 17 / 52$ & $32 / 24 \pm 22 / 25$ & $0 / 841$ & $0 / 568$ & 14 \\
\hline Pain & $39 / 38 \pm 13 / 36$ & $37 / 84 \pm 25 / 25$ & $0 / 741$ & $1 / 25$ & 14 \\
\hline General Health & $35 \pm 33 / 25$ & $40 / 21 \pm 17 / 24$ & $0 / 651$ & $0 / 256$ & 14 \\
\hline Quality of Life in General & $41 / 14 \pm 18 / 25$ & $39 / 32 \pm 20 / 21$ & $0 / 315$ & $1 / 25$ & 14 \\
\hline Depression & $24 / 93 \pm 2 / 17$ & $25 / 18 \pm 1 / 47$ & $0 / 841$ & $0 / 568$ & 14 \\
\hline
\end{tabular}

Table 4. The results of covariance analysis of different areas of depression and the quality of life in the control and experimental groups in the post-test

\begin{tabular}{|l|c|c|l|l|}
\hline \multirow{2}{*}{\multicolumn{1}{|c|}{ variables }} & \multicolumn{2}{c|}{ Standard Deviation \pm Mean } & \multicolumn{2}{c|}{ Covariance } \\
\cline { 2 - 5 } & $\begin{array}{c}\text { Experimental } \\
\text { Group }\end{array}$ & Control Group & significance & f \\
\hline Physical performance & $61 / 45 \pm 21$ & $49 / 21 \pm 16 / 25$ & $\leq 0 / 001$ & $41 / 14$ \\
\hline Physical Health Limitation & $49 \pm 20 / 45$ & $39 / 25 \pm 14 / 26$ & $0 / 001$ & $14 / 35$ \\
\hline $\begin{array}{l}\text { Emotional Problems } \\
\text { Limitation }\end{array}$ & $58 / 10 \pm 17 / 32$ & $34 / 25 \pm 18 / 18$ & $\leq 0 / 001$ & $45 / 13$ \\
\hline Strength/Fatigue & $55 / 20 \pm 29 / 55$ & $40 / 51 \pm 28 / 24$ & $0 / 001$ & $21 / 25$ \\
\hline Mental Health & $58 / 58 \pm 26 / 64$ & $43 / 84 \pm 14 / 21$ & $0 / 002$ & $10 / 49$ \\
\hline Social Performance & $49 \pm 19 / 14$ & $32 / 24 \pm 22 / 25$ & $\leq 0 / 001$ & $25 / 23$ \\
\hline Pain & $54 / 56 \pm 25 / 54$ & $37 / 84 \pm 25 / 25$ & $0 / 001$ & $43 / 14$ \\
\hline General Health & $52 / 50 \pm 24 / 65$ & $40 / 21 \pm 17 / 24$ & $\leq 0 / 001$ & $12 / 39$ \\
\hline Quality of Life in General & $57 / 25 \pm 12 / 09$ & $39 / 32 \pm 20 / 21$ & $0 / 000$ & $73 / 45$ \\
\hline Depression & $11 / 18 \pm 3 / 25$ & $25 / 18 \pm 1 / 47$ & $0 / 000$ & $58 / 84$ \\
\hline
\end{tabular}

The results of covariance analysis in table 4 is indicative of the fact that there is a significant difference between mean of different areas of depression and the quality of life in the control and experimental groups in the t-test $(\mathrm{P}<0.05)$. That is to say, the variables investigated in this study have been improved significantly in the experimental group.

\section{DISCUSSION AND CONCLUSION:}

The results of the current study indicated that 8 weeks of water-based physical therapy led to a significant improvement in different areas of depression and the quality of life within the experimental group while no tangible change appeared in any of the variables. Furthermore, comparison of the factors measured for both the control and experimental groups in the post-test was indicative of a significant difference between the two groups. This improvement is similar to the results attained in other studies where hydrotherapy has resulted in the improvement of the quality of life and emotional-mental state of the subjects(see $31,32,33,34,37$ ).The results of the 
current research correlate with the study by Lim et.al. (2010) which maintaineda water-based exercise program ends up in the improved quality of life for the elderly women with knee osteoarthritis ${ }^{49}$.Wang et.al. (2011) demonstrated in their study that water-based exerciseleaves low to moderate effects on the performance and the quality of life as well as a slight effect on pain intensity in the elderly people suffering from chronic pains.

Besides, in other similar studies, Heywood and Heinmann (2007) demonstrated that waterbased exercise proves effective in alleviating the pain and improving the quality of life for the elderly with chronic illnesses through strengthening the muscles around the joints and lifting off the pressure on them ${ }^{44}$. In South Korea, Kang (2008) showed that water-based exercise programs have been administered extensively in recent years to cure elderly chronic illnesses such as discopathy and osteoarthritis ${ }^{45}$. In a study titled "Hydrotherapy versus conventional land-based exercise for the management of patients with osteoarthritis of the knee: a randomized clinical trial", Silva et.al. maintained that exercise in water brings about a significance progress in ameliorating the pain intensity, disease symptoms, motor performance, and the quality of life in the elderly individuals with knee osteoarthritis ${ }^{47}$.

The study by Cider et.al. (2003) observed that hydrotherapy could be as well tolerated by the elderly patients or those with chronic illnesses as floating in water results in an increase in musculoskeletal and cardiovascular performance and a reduction of mental-emotional problems like stress and depression, subsequently boosting the patient's quality of life ${ }^{31}$.

The results of the study by Barker et.al. (2003) indicated that hydrotherapy for 2 weekly sessions during 8 weeks could reduce the fatigue in patients with chronic backache induced by pain, muscular spasms, and inability to do the daily routines. On the one hand, the patients in the study reported that doing water based exercise is a lot easier for them than land-based exercise so that even at times they are not able to do these exercises on the land ${ }^{32}$. Recent studies have reported the multiple benefits of exercise in water for the elderly people including reduction of postural fluctuations ${ }^{35}$, reduction of blood lipids, and increase in the maximum oxygen consumed, strength, muscular endurance, flexibility, and stability ${ }^{36}$ coupled with more independence in doing daily routines and, consequently, promotion of the quality of life ${ }^{37}$. The results of the current study are consistent with that by Abbasi et.al. (2012) investigating the effects of a hydrotherapy course on the stability of the elderly males, showing that water-based exercise would lead to improved stability and walking in the old people. They believed physical properties of water are the cause of reduction in falling down, increase in self-confidence for better walking, and finally, a more desirable quality of life among the elderly ${ }^{40}$. Authors of the present article also think of the alleviation of pain in the knees and back, improvement in walking, and increase in self-confidence for doing the daily routines as among the important causes of improvement in the quality of the elderly life. Typically, the study was conducted on the old people with chronic physical pains in knee or back where the majority of them believed after the end of the course that their physical pains are all gone or greatly alleviated. These are consistent with the results by Mohammadzadeh (2007) as they showed that a hydrotherapy course has proved effective in reducing the stress and alleviating the pain in the elderly people suffering from chronic rheumatoid arthritis ${ }^{41}$. Quite the contrary, the research results did not correspond to those of Chu et.al. (2004) where the 8 week water-based exercise exerted no significant effect neither onreducing the chronic physical pains nor on the stability of those developing the heart attack, although some significant recovery from cardiovascular vulnerability was observed ${ }^{42}$.

At the initial stage of the current study, the subjects had a low quality of life, yet with time and through participating in the exercise sessions, their condition gradually improved. They would say that being in the company of people with a condition similar to theirs prompts them to show up with more enthusiasm and energy in the sessions. The same applies to other studies ${ }^{38}$. One psychological benefit of exercise is its social dimension. While doing the exercise, the individual has to interact with other individuals with whom he might have many things in common. In this way, the individual feels he lives with his/her friends in one group doing some beneficial thing where he feels less lonely. This process is called socialization which is one variable multi- 
dimensional aspect of the quality of life ${ }^{38,39}$. Another psychological benefit of exercise is improvement of self-esteem and self-confidence. That is, following participation in sport activities the individual feels he/she has the same capabilities as others. That way, he feels more selfconfident. Developing a better picture of one's physical condition and the capability to better cope with problems related to physical health are among the cases improved by the individual's physical activity and sports interactions 39 . The hydrotherapy environment in the study appears to have been effective in the interaction among the individuals for sharing with one another their problems and limitations to find solutions for them.

Hydrotherapy has been developed on the basis of hydrostatic theory. The hydrostatic pressure caused by floating of the organs or the whole body on the water results in producing physiological responses focused on blood circulation system, so that the resultant hydrostatic pressure drives the blood from the lower organs up to the stomach and the upper body. As a result, with an increase in venous return to the heart it increases the heart beat volume, cardiac output, and perfusion to the organs. On the one hand, being floated on water can affect the emotional-mental problems of the individual by creating some sort of a mental vacuum, reducing the mentalemotional pressures, and partially reducing the secretion of epinephrine ${ }^{32}$. Exercise in water reduces the heartbeat, workload of the heart, and the amount of oxygen consumed during water-based exercise compared to the land-based exercise ${ }^{23}$. Most of the elderly people in this study complained about the chronic knee and back illnesses; by setting foot into water, they pursued their exercises with much ease and no or little pain owing to the principle of weightlessness in water. What was just described seems to have a great effect on boosting their morale and self-confidence. Presence of pain, inappropriate appearance, concern for more injury and incapability, high costs of treatment, and other probable factors would severely affect the quality of life for the old people and those surrounding him. With time, the subjects gained more assurance about the efficiency of the exercises by observing improvements in their physical condition which prompted them to show up in the following sessions with more enthusiasm. An improvement in all areas of the quality of life in the experimental group patients within a relatively short period of time signifies the efficiency of water-based physical therapy for the old people with chronic physical illnesses, while the subjects in the control group witnessed reductions in some areas.

It appears that chronic physical pains cause the elderly people to be more dependent on others for their daily routines which certainly affects their quality of life and mental-emotional factors. Therefore, in caring for this portion of the elderly population, exercises appropriate to their physical and mental condition must be given more consideration. Due to the limitations of this study, variables such as the level of income, education, professional background, and the like were not investigated. It is likely that investigating them will help better clarify other aspects of the quality of elderly life. The present statistics indicate that the demographic composition of the country is currently dominated by the young generation, yet in the near future, the now young people get old, and our country, like many others, will go through aging. It is, therefore, necessary to deal with these variables and topics in the future studies, and macro economic, social, and cultural planning be formulated in a manner to attend to the special needs of the old people; founding special fitness and health centers for the elderly can be an effective contribution in that regard. Given the benefits of hydrotherapy including easy training, cost effectiveness, no need for special equipment, and the results of the current study, it is suggested that the authorities seize the opportunity to improve the physical and mental health condition, and consequently improve the quality of life for the elderly people with chronic physical illnesses by providing proper facilities and exercise environments, particularly, hydrotherapy clinics specifically designated for performing easy and exhilarating exercise for the senile people. 


\section{References}

[1] Osuli, P, (2005).Iranian elderly narrative statistics. Health, (139): 13.

[2] Mirzaei, M., Shams Qhfrkhy, Mehri (2005). According to census of population of elderly people in Iran from 1335 to 1385. Elder Journal (Journal of Ageing) 0.2 (5): 326-331.

[3] Rokooei, Leila, \& Ghaffar Pour kimyagar (2006). aging power in Tehran in 1376. Publications familiar, Tehran.

[4] Ebersol P, Hess P (1990). Toward Healthy Aging, human needs and nursing responses. 3rd ed. St. Louis. The CV Mosby Company.

[5] Canbaz S, Sunter AT, Dabak S, Peksen Y (2003). The prevalence of chronic disease and quality of life in elderly people in Samsun. Turk J med Sci. 33(5): 335-340 .

[6] Lee T.W, Ko Is, Lee, kJ (2005). health promotion behaviors and quality of life among community dwelling elderly in Korea. International journal of nursing studies.; 49(2): 129-137.

[7] Felker B, Katon W, Hedrick SC, et al ( 2001). The association between depressive symptoms and health status in patients with chronic pulmonary disease. Gen Hosp Psychiatry. Apr; 23(2): $56-61$.

[8] Barry PP (2000). An overview of special considerations in the evaluation and management of the geriatric patient. Am J Gastroenterol. 95(1): 8-10.

[9] Conger SA, Moore KD (2002).Chronic illness and quality of life: the social workers role. TSAO foundation;. P. 1.

[10] Matteson MA, McConnell ES (1988).Gerotological Nursing. Philadelphia: Saunders.

[11] American Psychiatric Association (1995). Diagnostic and Statistical Manual of mental disorders. Translation Nykkhv, Vadys and Naqshbandi, speak Publications, Tehran.

[12] Myrzmany, Mahmoud, Hellisaz, Mohammad Taghi Sadidi, Ahmad \& Safari, Akbar (2008). Comparison of the effect of pain on various aspects of life, the elderly and people with chronic pain, elderly, Journal of Ageing. 3 (7) :48-57.

[13] Gasma A (1990). Is emotional disturbance a precipitator or a consequence of chronic pain? pain, 42،183-195.

[14] Newman, S. J., Struck, R., Wright, P. \& Rice, M. M (1990). Overwhelming olds: Care giving and the risk of institutionalization. Journal of Gerontology, 45, 173-183.

[15] Ghasemi, Sima and Moussaoui, Najm Sadat (2000). Health guide for seniors, topped Library Publications, Tehran.

[16] Oliver, JP. Huxley, P. \& Bridges, K (1997). Quality of life and mental health services. 1st ed. London: Routledge.

[17] Apolone G, Mosconi P. (1998). Review of the concept of quality of life assessment and discussion of the present trend in clinical research. Nephrol Dial Transplant. 13 (1):65-9.

[18] Beers MH, JonesTV, Bekwits ML, KaplanJ, Porter R.(2000) MerckManual of Geriatric . 3ed. Canada .Merck \& Co; Section 4.Chapter 33 - 34 - 40.

[19] Geriatric Mental Health Foundation (2008). Depression in late life: not a natural part of aging. Available at http://www.gmhfonline.org/gmhf/consumer/factsheets/depression_latelife.html

[20] Manzori.L,Babak.A,Marasi.M, Depration and connected effectson Esfehan old residents at year 1386 , Salmand, winter 1388

[21] Black JM, Hawks JH, Keene AM (2001). Medical surgical nursing. Sixth edition. Philadelphia: WB Saunders 
[22] Stenstrom CH (1994). Home exercise in rheumatoid arthritis functional class II: goal setting versus pain attention. J Rheumatol;21:627-34.

[23] Mcllveen B, Robertson J.V (1998). A randomised controlled study of the outcome of hydrotherapy for subjects with low back or back and leg pain. Physiotherapy; 84(1): 17-26.

[24] Geytenbeek J (2002). Evidence for effective hydrotherapy. Physiotherapy; 88 (9): 514-529.

[25] Carolyn E, Booth RN (2004). Water exercise and its effect on balance and gait to reduce the risk of falling in older adults. Activ Adapt Aging; 28: 45-57.

[26] Ware JE Jr, Sherbourne CD (1992). The MOS 36-item shortformhealth survey (SF-36). Conceptual framework and itemselection.Med Care; 30: 473-483.

[27] Eshraghi SR, Ramezani MA, Shahsanaee A, Pooya A (2006).Validity and reliability of the short form-36 items questionnaire asa measure of quality of life in elderly iranian population. Am JAppl Sci; 3: 1763-1766.

[28] Aben I, Verhey F, Lousberg R, Lodder J, Honig A (2002). Validity of the beck depression inventory, hospital anxiety and depression scale, SCL-90, and hamilton depression rating scale asscreening instruments for depression in stroke patients. Psychosomatics; 43: 386-393.

[29] Thomas F, Deborah D, Dianne LC (1992). Reliability and validity of the beck anxiety inventory.Anxiety Disord; 6: 55-61.

[30] Azkhvsh M (1387). Use of psychological tests and clinicaldiagnosis. Tehran, Psychology, Third printing, 226-224. (Persian).

[31] Cider A, Schaufelberger M, Stibrant Sunnerhagen K, Andersson B (2003). Hydrotherapy-a new approach to improve function in the older patient with chronic heart failure. The European Journal of Heart Failure; 5: 527-535

[32] Barker LK, Dawes H, Hansford P, Shamley D (2003). Perceived and measured levels of exertion of patients with chronic back pain exercising in a hydrotherapy pool. Arch Phys Med Rehabil September; 84: 1319-1323.

[33] ghafari.S,Effect of hydrotherapy on qualities life in patient with multiple Sclerosis, Rehabilitation, No.3 \& 4, winter 1387.

[34] Kargarfard.M,Effects of aquatic exercise therapy on quality of life,anxiety and deprassion in patients with Hemopilia, koomesh 0,cover12,No.4 summer 1390.

[35] Lord S, Mitchell D, Williams P (1993). Effect of water exercise on balance and related factors in older people. Australian Physiotherapy; 39: 217-217.

[36] Jones CJ, Rose DJ (2005). Physical activity instruction of older adults. Human Kinetics.

[37] Rissel C(1987). Water exercises for the frail elderly: a pilot programme. Auast J Physiother; 33: 226-232.

[38] Beeton K, Neal D, Lee C(2005). An exploration of healthrelated quality of life in adults with haemophilia. Haemophilia; 11: 123-132.

[39] Von mackensen (2007). Quality of life and sports activities in patients with haemophilia. Haemophilia; 13: 38-43.

[40] Abbasi.A,ABT impact on neurological function \& excersise - muscleand balancein older men, koomesh, cover 13,No.3,spring 1391.

[41] Mohammadzadeh, The effect of water treatment on pain relieaf and increased range of motion in the joints of people with Rheumatoid Arthritis,Medical Science Journal of Islamic Azad University, cover 17, No.13, autumn 1386. 
[42] Chu KS, Eng JJ, Dawson AS, Harris JE, Ozkaplan A, Gylfadóttir S(2004). Water-based exercise for cardiovascular fitness in people with chronic stroke: a randomized controlled trial. Arch Phys Med Rehabil; 85: 870-874.

[43] Belza B, Topolski T, Kinne S, Patrick DL, Ramsey SD(2002). Does adherence make a difference? Results from a community-based aquatic exercise program. Nurs Res; 51: 285-291.

[44] Hinman RS, Heywood SE, Day AR(2007). Aquatic physical therapy for hip and knee osteoarthritis: results of a single-blind randomized controlled trial. Phys Ther; 87: 32-43.

[45] Kang HS(2008). Factors influencing aquatic exercise adherence of patients with arthritis. J Korean Acad Fundam Nurs; 15: 350-9.

[46] Wang TJ, Lee SC, Liang SY, Tung HH, Wu SFV, Lin YP(2011). Comparing the efficacy of aquatic exercises and land-based exercises for patients with knee osteoarthritis. J Clin Nurs; 20: 2609-22.

[47] Silva LE, Valim V, Pessanha AP, Oliveira LM, Myamoto S, Jones A \& Natour J(2008). Hydrotherapy versus conventional land-based exercise for the management of patients with osteoarthritis of the knee: a randomized clinical trial. Phys Ther; 88: 12-21.

[48] Lund H, Weile U, Christensen R, Rostock B, Downey A, Bartels EM, et al(2008). A Randomized controlled trial of aquatic and aland-based exercise in patients withknee osteoarthritis. J Rehabil Med; 40: 137-144.

[49] Lim JY, Tchai E, Jang SN(2010). Effectiveness of Aquatic Exercise for obese patientswith knee osteoarthritis: A randomized controlled trial. the American Academy of Physical Medicine and Rehabilitation; 2: 723-31. 